\title{
ENTRE A TEORIA E O MÉTODO: \\ a interpretação da teoria de Emilia Ferreiro pelas alfabetizadoras
}

\author{
Fernanda Cargnin Gonçalves ${ }^{1}$
}

\section{RESUMO}

O presente artigo tem por objetivo mostrar a dificuldade de compreensão da teoria de Emilia Ferreiro por professoras de primeira série de uma escola da rede pública municipal da cidade de Florianópolis/SC. Apresenta a real teoria de Ferreiro descrita em seu livro "Psicogênese da Língua Escrita", em co-autoria com Teberosky, e a interpretação das alfabetizadoras observadas em suas práticas de ensino. Há também alternativas de trabalho para se alfabetizar uma criança que foge da rotulação dos estudantes em fases de alfabetização, e que são baseadas em textos teóricos, mostrando que é possível alfabetizar sem transformar teoria em método.

Palavras-chave: alfabetização, teoria de Emilia Ferreiro, práticas de ensino em classes de alfabetização.

$\mathrm{Na}$ rotina diária de qualquer escola, inúmeros dilemas podem ser observados. Não existe escola sem problemas, conflitos e divergências; sempre há o que resolver seja, em relação aos alunos, professores, funcionários, conteúdos, métodos de ensino e tudo o que envolve o espaço educacional. Percebemos em um curto espaço de tempo todas estas problemáticas durante o estágio realizado dentro da Disciplina Prática de Ensino da Escola de Ensino Fundamental - Séries Iniciais ${ }^{2}$.

Dentre os diversos contratempos que acontecem em sala de aula, estão as dificuldades de aprendizagem notadas em vários alunos com problemas das mais variadas origens; a violência entre as crianças, principalmente em espaços abertos como no Recreio e na Educação Física; a falta de formação continuada adequada dos professores, que gera problemas na hora de ensinar; os inúmeros imprevistos do dia-adia, como falta de água e ausência de professores; dificuldades relacionadas à avaliação da aprendizagem das crianças e ao melhor método a ser aplicado; a falta de incentivo das famílias em relação ao estudo dos seus filhos; a dificuldade de entender o que acontece na vida e na mente de cada criança, e inúmeros outros dilemas.

\footnotetext{
1 Aluna da oitava fase do curso de graduação em Pedagogia - habilitação em Educação Infantil, da Universidade Federal de Santa Catarina.

${ }^{2}$ Disciplina do curso de Pedagogia da Universidade Federal de Santa Catarina, realizada na Escola Desdobrada Municipal Adotiva Liberato Valentin no ano de 2007.
} 
Uma das limitações flagrantemente observadas na escola mencionada é o uso inadequado da teoria de Emilia Ferreiro no processo de alfabetização. As professoras de

Primeira Série se apropriam dos termos descritos pela autora de uma forma questionável, sem terem uma fundamentação teórica suficiente para os utilizarem em sala de aula. Tal incoerência pôde ser constatada por meio das observações das atividades, avaliações e prática de ensino das docentes da Escola Adotiva.

As educadoras usam a teoria de Ferreiro, quando ela trata das fases da escrita espontânea das crianças. Isto aparece em várias de suas obras, especialmente na Psicogênese da Língua Escrita, em co-autoria com Teberosky (1985).

O livro diz que, ao longo da alfabetização, a criança passa por cinco níveis progressivos. No primeiro, a criança tem sua própria escrita, e só ela pode interpretá-la. Sua escrita se assemelha à forma gráfica que a criança tem contato, se for a cursiva o traço é uma linha ondulada, se letra de imprensa, a criança faz linhas retas e curvas separadas. Na maioria das vezes existe diferenciação entre desenho e escrita, a criança faz rabiscos distintos dos desenhos representando a escrita, que já é linear. Contudo, nessa mesma fase podem acontecer indiferenciações momentâneas entre o icônico e o não-icônico, com o desenho servindo de apoio para o significado da escrita.

Nesse nível, a criança só se permite usar uns números mínimos e variados de caracteres, que normalmente é constante, mas pode mudar de acordo com o tamanho do objeto escrito.

Na segunda fase, os grafismos são mais próximos das letras, e também há uma exigência por parte das crianças do uso de um número mínimo de caracteres. Além disso, são usadas somente as grafias conhecidas; por isso, a criança diferencia as letras em uma mesma palavra, mas em palavras diferentes os grafemas usados são o mesmo, só as ordens deles são alteradas. Essa característica pode gerar um bloqueio na criança, fazendo com que escreva somente seguindo um determinado modelo.

Esses dois níveis se enquadram em uma escrita global e estão dentro da fase présilábica, que é procedida pela fase de fonetização, dividida em hipóteses silábica, silábico-alfabética e alfabética.

$\mathrm{Na}$ hipótese silábica, começa a existir certa correspondência entre letra e som. Aqui a criança escreve uma letra para cada sílaba, apesar de as letras poderem ser as mesmas para representarem diferentes silabas. As grafias podem ser diferentes ou iguais, convencionais ou não, e é mantido um número mínimo de caracteres. Entretanto, essa exigência pode desaparecer momentaneamente. Por conta disso, o indivíduo passa 
por conflitos quando se depara com dissílabos e monossílabos, já que terá que escrever palavras com uma ou duas letras. Para resolver esse dilema, a criança acrescenta mais letras à palavra e denomina a sobra como algo que se relaciona com a escrita original. A partir do momento em que a criança começa a usar a mesma letra para uma específica sílaba, surgem outros problemas, e para superá-los ela pode intercalar com as sílabas uma letra "coringa".

Em seguida, a criança passa por uma hipótese de transição, que é a silábicoalfabética. Ela começa a viver um conflito entre a hipótese silábica e as formas gráficas observadas na sociedade, descobrindo que é preciso fazer uma análise maior da palavra, e que a sílaba é formada por unidades menores. Entretanto, ainda não tem o conhecimento do meio, e acaba apenas duplicando a quantidade de letras por sílaba (FERREIRO 1993).

Por fim, na hipótese alfabética a criança já consegue fazer uma clara correspondência grafofonêmica. Ela adquire a escrita aceita pela sociedade, e só possui dificuldades de ordem ortográfica, não existindo mais dificuldades com o código.

Para formular essa teoria, Ferreiro e Teberosky (1985) pesquisaram com a ajuda de crianças que ainda não estavam na escola. Contudo, ao trabalharem com outras já dentro de uma instituição de ensino, comprovaram que a situação não é muito diferente. $\mathrm{Na}$ escola, a criança também passa por todas as fases. Umas já começam a vida escolar com algumas ou todas as hipóteses internalizadas, o que facilita o processo de aprendizagem. Já outras têm mais dificuldade por não possuírem quase nenhum conhecimento prévio, pois assim terão que passar por todas as hipóteses descritas acima durante a alfabetização. São essas as crianças que mais precisam do ensino escolar.

As professoras da Escola Adotiva adotaram as fases silábica, silábico-alfabética e alfabética para avaliar seus alunos, ou seja, realizaram uma avaliação diagnóstica. Durante a observação do estágio, pôde-se perceber que são feitos pequenos testes com todos os estudantes. A professora corrige e depois insere o nome da criança em uma tabela constando as hipóteses de alfabetização. Uma outra professora da Primeira Série usa metaforicamente uma "escada", cujos degraus correspondem a cada fase em que a criança está. Quando algum aluno "passa” para o estágio seguinte, a docente anuncia para a turma inteira o suposto progresso.

Ao lermos a Psicogênese da Língua Escrita, observamos que Ferreiro diz que as fases de alfabetização realmente acontecem de forma regular, uma seguida da outra. Contudo, em outras obras (FERREIRO, 1990; 1993), a própria autora explica melhor o 
que disse, afirmando que os resultados obtidos com a pesquisa poderiam ser outros, caso o público estudado fosse diferente. Afirma também que há crianças que pulam fases, e a maioria delas possui características de uma hipótese, e em seguida escreve de acordo com outra, podendo até voltar em alguns momentos para a fase anterior. Além disso, na própria Psicogênese da Língua Escrita percebemos as diferenças de etapas dentro das classes sociais: crianças que possuíam maior contato com a leitura e a escrita desde pequenas, normalmente as da classe média, alcançavam fases mais avançadas com maior facilidade.

Com a entrada da teoria de Emilia Ferreiro no Brasil no final da década de 1980, muitos educadores apropriaram-se das novidades em alfabetização de forma equivocada. As proposições teóricas transformaram-se em método, ou seja, as pessoas internalizaram essa teoria rapidamente, sem refletir muito sobre ela, em decorrência da urgência em superar o fracasso escolar que estava acontecendo em toda a América Latina (FERREIRO 1990).

Houve uma transferência direta do psicológico para o pedagógico. Todas as professoras passaram a ver crianças silábicas, silábico-alfabéticas e alfabéticas. Porém, pedagogia e psicologia são coisas diferentes; é preciso investigar aspectos da primeira a partir da teoria da segunda (FERREIRO 1990).

Existem muito professores que são construtivistas de ouvido; apenas ouviram falar de Ferreiro, de hipóteses de alfabetização em um curso de capacitação dos órgãos públicos ou da escola, ou tiveram informações através de um colega de trabalho, e já colocam em prática algo que mal conhecem. Poucos professores da rede pública, que usam esta teoria como método de ensino, leram um livro de Ferreiro; se o fizeram, a leitura foi apenas de um fragmento. É verdade que essas professoras possuem uma carga de trabalho muito alta, em geral quarenta horas por semana, e por isso não conseguem tempo para estudar o embasamento teórico da sua prática de ensino.

Entretanto, Ferreiro e outras autoras (1990) afirmam que o professor precisa refletir sobre sua prática, e para isso é necessário existir um referencial teórico que possibilite a análise sobre a eficácia e o sentido daquilo que se está fazendo. É a teoria que dá um substrato para a prática.

A partir das observações realizadas, inferimos durante o estágio que as professoras da Escola Adotiva não demonstram preocupação com a teoria e a reflexão sobre a prática pedagógica. Essas profissionais ainda não compreenderam que os níveis de conceitualização servem apenas para conhecimento do professor, e não para rotular 
os alunos, mas formar grupos heterogêneos para ajudá-los. Além disso, as fases servem para os professores proporem atividades para os alunos avançarem, e não para aplicarem exercícios que se restrinjam à hipótese em que a criança se encontra. Devem ser usados textos que façam sentido e não palavras, sílabas ou letras soltas, pensando que a criança não consegue compreender mais do que isso porque está nesse ou naquele nível (BARREIRA, 1991).

No período de estágio, também observamos que mesmo as crianças intituladas alfabéticas possuem sérios problemas de leitura e escrita. Elas até conseguem decifrar o código, mas ainda não têm condições de formular textos criativos e coerentes. Um exemplo desse problema pode ser visto na confecção dos panfletos de propaganda da escola. Quando solicitados para escreverem uma frase sobre o espaço, pessoa ou atividade que escolheram, os alunos se restringiram a produções como: "A quadra é bonita", "O parque é bonito", “A quadra é legal”, "A professora é bonita”.

Para tentar diminuir os problemas de alfabetização de seus alunos, as professoras de Primeira Série podem ir além dos exercícios propostos, que se confundem entre o método tradicional e a teoria construtivista. Duas opções seriam o ensino através de atividades práticas como base para a representação escrita e outras formas, e o trabalho com a escrita a partir da oralidade.

As crianças durante o período de estágio mostraram muito interesse pelos conteúdos práticos desenvolvidos em sala de aula ou fora dela, como por exemplo nas atividades sobre solo, em que os alunos mexeram nas amostras de terra que trouxeram de casa e depois registraram suas observações. De acordo com o registro do dia dezenove de outubro:

[...] Um grupo ficou impressionado porque encontrou minhocas e formigas na terra, outro que tinha em mãos solo argiloso percebeu que ele era parecido com a argila que eles usavam para brincar [...] Percebi também que quando as atividades são práticas e as crianças visualizam aquilo que está sendo falado, fica muito mais fácil ensinar e aprender (Registro diário de estágio - 19/10/07).

Um outro trabalho prático feito com as crianças foi a filmagem de propaganda da escola. O interesse foi de todos; os alunos ficaram muito interessados e nervosos com a idéia de serem filmados. Pôde-se também perceber um pouco da personalidade das crianças e a sua origem. Observemos o registro de estágio a seguir: 
Durante as filmagens pude perceber um pouco da personalidade de cada aluno, os tímidos, os extrovertidos, os distraídos, os que só repetiam o que o amigo falava, como o Rian e o Eduardo. Consegui também identificar a diferença entre as classes sociais das crianças; os que os pais possuem um poder aquisitivo um pouco maior, não se impressionavam tanto com a máquina e com o que estavam fazendo, já outros ficaram encantados, como o Ruan, que na hora em que mostrei a filmadora para ele e deixei que mexesse ficava sempre repetindo: "Que legal 'sora'!", e quando voltamos para a sala perguntou se não ia ter mais (Registro diário de estágio - 26/10/07).

Essa perspectiva de utilização da prática para ensinar foi abordada por Freinet (1998), através do trabalho com oficinas. Ele afirma que a criança não acredita em tudo o que falamos; ela precisa experimentar, ter contato com trabalhos manuais para adquirir um conhecimento pleno e depois representá-lo usando várias linguagens, entre elas a escrita:

Está mais do que na hora de corrigir tais erros, de começar pelo começo, de oferecer à infância os trabalhos pelos quais ela sente sempre total atração; de esperar atividades das quais resultarão a adaptação ao meio, o assentamento essencial na vida, o elemento natural da ordem, o impulso motor primordial, a exacerbação do sentimento de potencia que infunde ousadia, confiança, audácia, bom humor e alegria (FREINET, 1998, p.380).

Uma alternativa para melhorar a escrita e a leitura das crianças em processo de alfabetização é a estimulação da linguagem oral. Para melhor transpor a linguagem oral para a escrita, a criança deve estar inserida em um ambiente letrado, e por isso, a sala de aula e a escola como um todo, devem ser repletas de material escrito, como, por exemplo, placas informativas, uso dos nomes das crianças e cartazes. Também devem existir locais e atividades propícias para a estimulação da leitura (ALLIENDE; CONDEMARÍN, 2005).

Inúmeras atividades podem ser realizadas para fazer com que a criança consiga mais facilmente relacionar letra e som. Alliende \& Condemarín (2005) dão alguns exemplos dessas possíveis estratégias de ensino. Dentre elas estão a contação e a leitura de histórias, que podem ser feitas através de um livro gigante ou vários livros, no(s) qual (is) todas as crianças conseguem acompanhar a leitura, observando cada palavra. A criança também pode brincar de ler, ou seja, com histórias, músicas, parlendas, rimas e trava-línguas conhecidos, ela vai olhando as palavras e dizendo em voz alta, já que decorou o texto escrito. 
Se fosse possível dar continuidade ao trabalho com a filmagem de propaganda da escola, a professora poderia relacionar a fala das crianças com a escrita, questionando como os alunos expressariam a mesma coisa que disseram através da escrita.

Um professor alfabetizador tem a sua disposição, inúmeras teorias que podem ajudá-lo no seu trabalho. Contudo, estas precisam ser bem estudadas e entendidas, para que eles não a interpretem erroneamente e caiam na tentação de utilizar apenas a parte mais fácil descrita por um certo autor, como aconteceu com a apropriação das idéias de Emilia Ferreiro, observada no período de estágio aqui descrito e discutido.

\section{BIBLIOGRAFIA}

ALLIENDE, F.; CONDEMARÍN, M. A leitura: teoria, avaliação e desenvolvimento. 8. ed. Porto Alegre: Artmed, 2005.

BARREIRA, Sonia Maria. Que didáticas podem ser geradas após a Psicogênese da Lingua Escrita? Revista Trino. São Paulo, Escola da Vila, 1991.

FERREIRO, Emilia. Reflexões sobre alfabetização. 22 ed. São Paulo: Cortez,1993. - (org.). Os filhos do Analfabetismo: propostas para a alfabetização escolar na América Latina. Porto Alegre: Artes Médicas, 1990.

FEEREIRO, Emilia \& TEBEROSKY, Ana. Psicogênese da língua escrita. Porto Alegre: Artes Médicas, 1985.

FREINET. Célestin. A Educação do Trabalho. São Paulo: Martins Fontes, 1998.

Registro diário de estágio - Séries Iniciais: 19/10/07

Registro diário de estágio - Séries Iniciais: 24/10/07

Registro diário de estágio - Séries Iniciais: 25/10/07

Registro diário de estágio - Séries Iniciais: 26/10/07

Registro diário de estágio - Séries Iniciais: 29/10/07 